\title{
Analysis of short fruiting branch gene and Marker-assisted selection with SNP linked to its trait in upland cotton
}

\author{
ZHANG Youchang ${ }^{1,2}$, FENG Changhui ${ }^{1,2}$, BIE Shu $^{1,2}$, WANG Xiaogang ${ }^{1,2}$, ZHANG Jiaohai ${ }^{1,2}$, XIA Songbo ${ }^{1,2}$ \\ and QIN Hongde ${ }^{1,2^{*}}$ (D)
}

\begin{abstract}
Background: With the rapid development of genomics, many functional genes have been targeted. Molecular marker assisted selection can accelerate the breeding process by linking selection to functional genes.

Methods: In a study of upland cotton (Gossypium hirsutum L.), the $F_{2}$ segregated population was constructed by crossing X1570 (short branches) with Ekangmian-13 (long branches) to identify the short fruiting branch gene and marker-assisted selection with SNP(Single Nucleotide Polymorphisms, SNP) linked to its trait.

Result: The result demonstrated that linked SSR marker BNL3232 was screened by BSA(Bulked segregant analysis, BSA) method; one SNP locus was found, which was totally separated from the fruiting branches trait in upland cotton.
\end{abstract}

Conclusion: It was verified that this SNP marker could be used for molecular assisted selection of cotton architecture.

Keywords: Short fruit-branch, Cotton, Gene, Marker-assisted selection

\section{Background}

Plant architecture is an important breeding target trait, and fruiting branch type is a primary determinant of plant architecture in upland cotton (Gossypium hirsutum L.). Fruiting branches, as the name implies, are fruit-bearing branches of cotton plants that can bear bolls and are usually located in the upper middle of the main stem. The short fruiting branch cotton type is identified by plants with only one to two fruiting positions per branch and short fruiting branch internodes (Du 1996). An advantage of this growth habit is that after cutting off the top of the plant, the plant does not continue to produce additional vegetative growth, concentrating nutrient and carbohydrate supply for developing bolls and accelerating boll maturation ( $\mathrm{Du}$ et al. 1996). In addition, plants with short fruiting branches allow additional light transmission into the plant canopy

\footnotetext{
*Correspondence: yzzsjc307@163.com

'Institute of Cash Crops, Hubei Academy of Agricultural Sciences, Wuhan 430064, Hubei, China

${ }^{2}$ Key Laboratory of Cotton Biology and Breeding in the Middle Reaches of the Yangtze River (Wuhan), Ministry of Agriculture, Wuhan, Hubei 430064, China
}

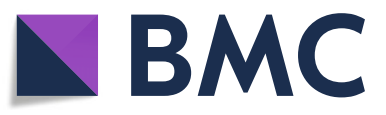

(c) The Author(s). 2018 Open Access This article is distributed under the terms of the Creative Commons Attribution 4.0 International License (http://creativecommons.org/licenses/by/4.0/), which permits unrestricted use, distribution, and reproduction in any medium, provided you give appropriate credit to the original author(s) and the source, provide a link to the Creative Commons license, and indicate if changes were made. The Creative Commons Public Domain Dedication waiver (http://creativecommons.org/publicdomain/zero/1.0/) applies to the data made available in this article, unless otherwise stated. Yang 2003). Plants with short fruiting branches also do not need pruning, which decreases inputs and improves production costs. Growth of leaves and branches can be controlled completely by high-density planting of short fruiting branch upland cotton, so that fertilizer demand is decreased compared with normal fruiting branch varieties (Yang et al. 2001).

Additionally, plant architecture is an important characteristic that affects cotton plant adaptability, yield, and fiber quality. An enhanced understanding of the molecular-genetic regulation of plant morphological developmental can aid in modifying relevant agronomic traits to obtain high yielding cotton varieties (Song and Zhang 2009). Moreover, with the change of the quantity and structure of the rural labor force in China, traditional labor-intensive management measures are losing their economic viability for cotton cultivation and production in the Yangtze River Basin of China. Selection of cultivars with short fruiting branches also allows less cultivation and chemical application, improving the environmental impact and sustainability of cotton fields in 
Yangtze River Basin of China. Cotton breeding should focus on those varieties suitable for shortening the cotton growing period, sowing after wheat or edible rape, and being picked by machine (Liu et al. 2013). Therefore, the short fruiting branch becomes an important selected target in cotton breeding (Zhang et al. 2006).

Classical genetic studies have shown that the traits of fruiting branch belong to quality traits. Cluster gene $c l 1$ and $c l 3$ from the upland cotton are located on Chromosome 16 (D07) (Hau et al. 1980; Silow 1946; Ni et al. 2007). The $c l 2$ gene from G. barbadense is located on Chromosome 7 (A07) (Thadani 1923). Hu (2016) established an $\mathrm{F}_{2}$ population from a cross between G.hirsutum mutant T586 and G.barbadense Hai7124 for rough mapping $\mathrm{cl}$ gene, and $\mathrm{cl}$ was located on the Chr16 chromosome and linked to SSR marker BNL1694 (Hu and Zhou 2006). In recent years, QTL mapping and sequencing techniques were used to finely map the short fruiting branch traits of Gossypium barbadense. $\mathrm{F}_{2}$ population was constructed by the nulliplex-branch Pima cotton variety, Xinhai-18 crossed with the normal branch upland cotton line, TM-1, the nulliplex-branch trait was found to be controlled by the recessive gene $g b \_n b 1$, localized at the $600 \mathrm{~kb}$ interval on Chr 16 (Chen et al. 2014); In 2015, $c l$ gene was mapped between maker SWU07707 and SWU08487 within an interval of $69 \mathrm{~kb}$ physical distance of G. raimondii genome, and there is only one annotated gene, Gorai.001G121800, which is associated with flowering time candidate gene (Zhai 2015). Although there are several SSR markers linked to short fruiting branch trait in G. barbadense, there are still no reports on the location and linkage markers of the short-branch trait gene of G. hirsutum. In this study, the sequence analysis and uncovering of markers linked to short fruiting branch traits derived from two G. hirsutum L. mutants were used to improve markers of the functional genes and make molecular marker-assisted selection in upland cotton.

\section{Methods}

Plant materials

In this study, parent cotton material X1570 and Ekangmian-13 were used for constructing population. Both belong to G.hirsutum. Ekangmian-13 was a national certified cotton variety by Huimin Agricultural in Hubei Province, and had normal fruiting branches with more than two nodes; X1570 is a type of early maturity material obtained from the Duck cotton which originated from Deltapine 15 (Yu and Liu 1957), and characterized by short fruiting branches trait with only 1-2 fruiting positions(Fig. 1). The growth period duration of X1570 is about 95-100 days, with 50 days of flowering time. The difference flowering time of the first position between two adjacent fruiting branches is 45 days, and the interval of flowering between two adjacent nodes of the same fruiting branch is only 1 2 days, less than with ordinary varieties of $5 \sim 7$ days (Bednarz and Nichols 2005). This feature which concentrates flowering and boll opening is suitable for cotton harvest by machine.

During flowering, the short fruiting branch trait was observed visually. It was found that X1570 flowered about 8-10 days earlier than Ekangmian-13 when planted in Hainan and Hubei province. An $\mathrm{F}_{2}$ population comprised of 155 plants through crossing X1570 with Ekangmian-13 was constructed for genetic analysis and locating the $c l$ gene with 367 SSR makers coming from Chr_16 to the reference of CMD (Cotton marker database)by using bulked segregant analysis based on molecular markers.

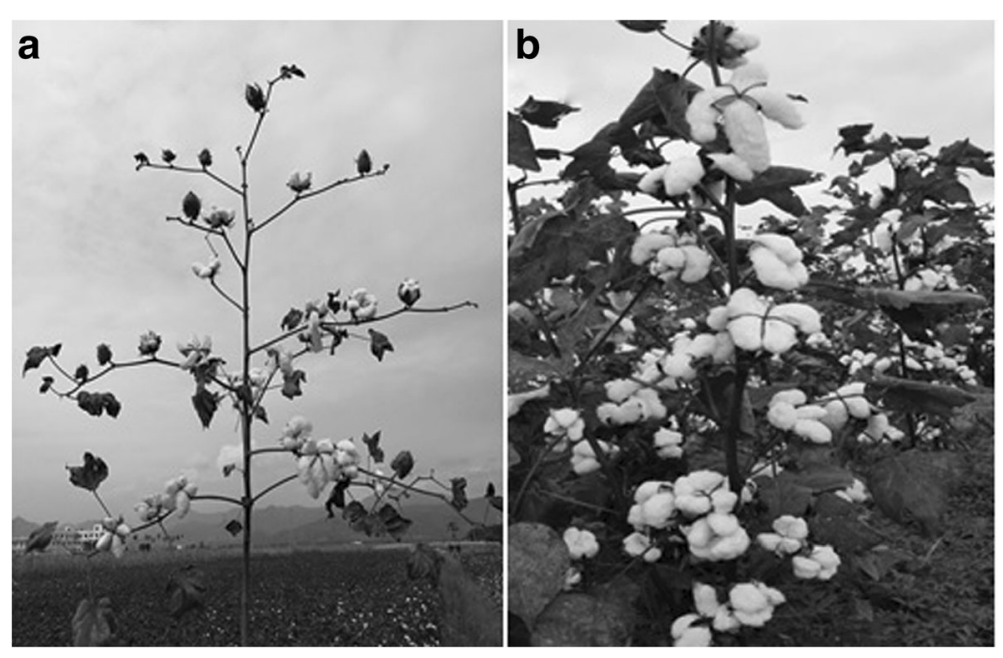

Fig. 1 a Ekangmian13 phenotype of opening boll; b X1570 phenotype of opening boll(Oct,2015) 


\section{DNA and RNA extraction}

Cotton genomic DNA was extracted using CTAB method, a cotton genomic rapid extraction method, according to Paterson's CTAB (Hexadecyltrimethyl ammonium bromide) method of 1993 (Paterson et al. 1993). RNA was isolated from young leaves using RNAprep Pure Plant Kit. DNA was quantified by a Nanodrop 2000 UV-Vis spectrophotometer machine; RNA was quantified by $18 \mathrm{~s}$ rRNA and $28 \mathrm{~s}$ rRNA in agarose gel electrophoresis.

\section{Distinguishing SNP locus with dCAPS makers}

Derived cleaved amplified polymorphic (dCAPS) is one of the methods to verify SNP loci. It is rare that the SNP is justly located at the restriction enzyme site. By bringing the mismatch base in the amplification primer on the basis of the Cleaved Amplification Polymorphism Sequence (CAPS) marker, a new SNP of the restriction endonuclease site can be formed to result in similar polymorphisms as CAPS markers, which is dCAPS method. SNP sites can be converted to PCR-based molecular markers by CAPS or dCAPS. Application methods and steps are as follows:

First, the dCAPS primer sequence (F: 5'-TTCA ACACCAACAAgCAGGT-3 '; R: 5’-ggTCACTAggACCAggAACAA-3') was designed based on the Gorai.001G121800_ATC gene contain SNP locus. Polyacrylamide gel electrophoresis was clear without polymorphism.

Second, the PCR production was digested with endonuclease enzymes Mun I in a water bath at $37{ }^{\circ} \mathrm{C}$ for $2 \sim 4 \mathrm{~h}$. The enzyme digestion systemis: Mun I $1 \mu \mathrm{L}$, $10 \times$ M Buffer $2 \mu \mathrm{L}, 0.1 \%$ BSA $2 \mu \mathrm{L}$, DNA $3 \mu \mathrm{L}$, Sterile water $2 \mu \mathrm{L}$.

Third, digested products were subjected to polyacrylamide gel electrophoresis, adding $2 \mu \mathrm{L}$ of loading buffer, electrophoresed in $8 \%$ polyacrylamide gel and $1 \times \mathrm{TBE}$ electrophoresis buffer. After electrophoresis was completed, the polyacrylamide gel was stained in $0.1 \%$ $\mathrm{AgNO}_{3}$ solution for $10 \mathrm{~min}$. Then, it was quickly washed twice with purified water and placed in the color reagent for $10 \mathrm{~min}$ until the electrophoresis strip was clear. Finally, it was cleaned by running water.

\section{Quantitative analysis of gene ATC by real-time PCR}

According to the results of blasting homologous gene sequence, the primers of Gorai.001G121800_ATC gene located on D07 were designed based on the conserved and specific (no homology with other genes) gene segments. PrimeScript ${ }^{\mathrm{tm}}$ RT reagent Kit with gDNA Eraser (Perfect Real Time) was used for fluorescence quantitative PCR analysis, the primers sequence are as follows:

ATCQ1F: CACCCTGGTGATGACAGACC. ATCQ1R: TGTTTGGCCTTGGCATTTCG. ATCQ2F: AGTGACAGATATCCCCGGCA. ATCQ2R: GCTTCTCACTGTTTGCCTGC.
Internal reference sequence: actin-F:TCACGGAAGCACCTCTCAAC. actin-R:ACAAAGAGAGAACGGCCTGG.

\section{Results}

Genetic analysis of the short fruiting branch trait

According to the chi-square test of the two types of branch traits in $F_{2}$ population, the segregation corresponded to the Mendelian segregation ratio of $3: 1\left(\chi^{2}=\right.$ $\left.0.286<\chi^{2}(0.05,1)=3.84\right)$ (Table 1$)$. The result indicated that the trait of short fruiting branch is a pair of recessive genes.

\section{Validation of SSR markers}

Classical genetic studies have shown that short fruiting branch trait is controlled by the gene originated from Chr_16 (Hau et al. 1980; Silow 1946) in G. hirsutum. BSA was used to rapidly identify 367 SSR markers, which were selected from Chr_16 of tetraploid cotton linked to the short fruiting branch trait. Thirty-three short fruiting branch plants (referred to as Sb pool) and 33 multiple node-branch plants (referred to as $\mathrm{Mb}$ pool) were randomly selected from the $F_{2}$ population, and an equal amount of DNA from each plant in each group was mixed to form two pools. The result (Fig. 2) showed that the SSR marker BNL3232 is linked to the short-fruiting branches,and the exchange ratio is only $7.6 \%$. Therefore, it is supposed that gene Gorai.001G121800_ATC originated from gene $c l 1$ in upland cotton.

\section{Analysis of ATC gene expression by RT_PCR}

Quantitative PCR results showed that the expression level of Gorai.001G121800_ATC gene was very low, the $\mathrm{Cq}$ value of Actin was only 20 , and the $\mathrm{Cq}$ value of Gorai.001G121800_ATC gene was about 35, which indicated that the abundance of ATC gene was very low, agreeing with previous results reported by Anagnostis Argiriou in 2008 (Argiriou et al. 2008). The expression level of this gene is also different in X1570 and Ekangmian-13 (as shown in Fig. 3), especially during the budding stage. The relative expression of the gene in leaves of Ekangmian-13 was significantly higher than in X1570, which had such little expression of this gene that it could not be detected by equipment. This indicates that the gene plays an important role in determining the type of fruit branch.

Table 1 Segregation ration of fruiting branch in $F_{2}$ population

\begin{tabular}{lll}
\hline Traits & Number & $x^{2}$ \\
\hline Normal branch & 122 & 0.286 \\
Short fruiting branch & 33 & \\
Total & 155 & \\
\hline
\end{tabular}




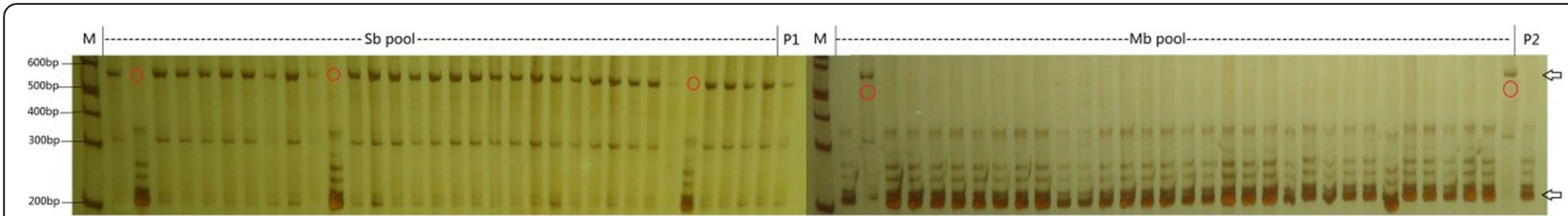

Fig. 2 Confirmation of linked SSR marker BNL3232 in 33 short-branch(Sb)and 30 normal plants(Mb)consisting of the Sb and Mb pools:Open arrows indicate polymorphic bands. Rings indicate recombinant plants. M: DNA ladder, P1:X1570, P2:EKangmian-13

\section{Sequence analysis of $A T C$ gene}

The DNA template isolated from parent plants of X1570 and Ekangmian-13 was selected to amplify the genome region between the ATG codon to TGA codon according to the open reading frame(ORF) of the ATC gene. The region contained the exon and intron segments and were respectively connected to the PMD18-T plasmid vector. Then, 6 positive clones selected from both amplified production above were sequenced, for a total of 12 . The primers are as follows.

\section{ATCF1 ATGGCAAAACTGTCAGATCCTCT.}

ATCR1 TTAGCGTCTTCTAGCAGCTGTTTC.

The Gorai.001G121800_ATC gene has a total length of $1052 \mathrm{bp}$ and contains four exons with a total length of $525 \mathrm{bp}$ and three introns with a total length of $527 \mathrm{bp}$. It encodes 175 amino acids and is homologous to Arabidopsis thaliana TFL1/ATC. The 12 pairs of sequences mentioned above was blasted by software DNAMAN. It could be seen that there were five positions where there was a base variation. They were on the 83 rd base of the first one exon, 371st base of the second exons, and 935th, 962rd, 992rd base of the fourth exon. However, only the base at position 371 of the second exon had mutations on X1570 and no mutation on Ekangmian-13, and the other four loci had mutations among the three upland cotton varieties. The Gorai.001G121800_ATC gene of 371 base of X1570 was characterized with G transferring $\mathrm{A}$, which resulted in amino acid arginine $(\mathrm{Arg})$ transferring lysine (Lys). It was guessed that the GA mutation loci from X1570 (shown in Fig. 4) created the short fruiting branch trait.

\section{Validation SNP marker by dCAPS}

The dCAPS primer sequence (F: 5'-TTCAACACC AACAAgCAGGT-3 '; R: 5’-ggTCACTAggACCAggAA CAA-3') was designed based on the Gorai.001G121800_ATC gene containing mutation SNP_GH1570. The production of PCR can be digested by Mun I enzyme from the SNP_GH1570 loci. Polyacrylamide gel electrophoresis was clear without polymorphism.

The results of dCAPS (shown in Fig. 5) indicated that a band restricted by enzyme Mun I at the position of $226 \mathrm{bp}$ appeared in the 30 plants with short fruiting branch randomly selected from $F_{2}$ of $\times$ $1570 \times$ Ekangmian-13. In contrast,there were no electrophoretic bands at the same position of $226 \mathrm{bp}$

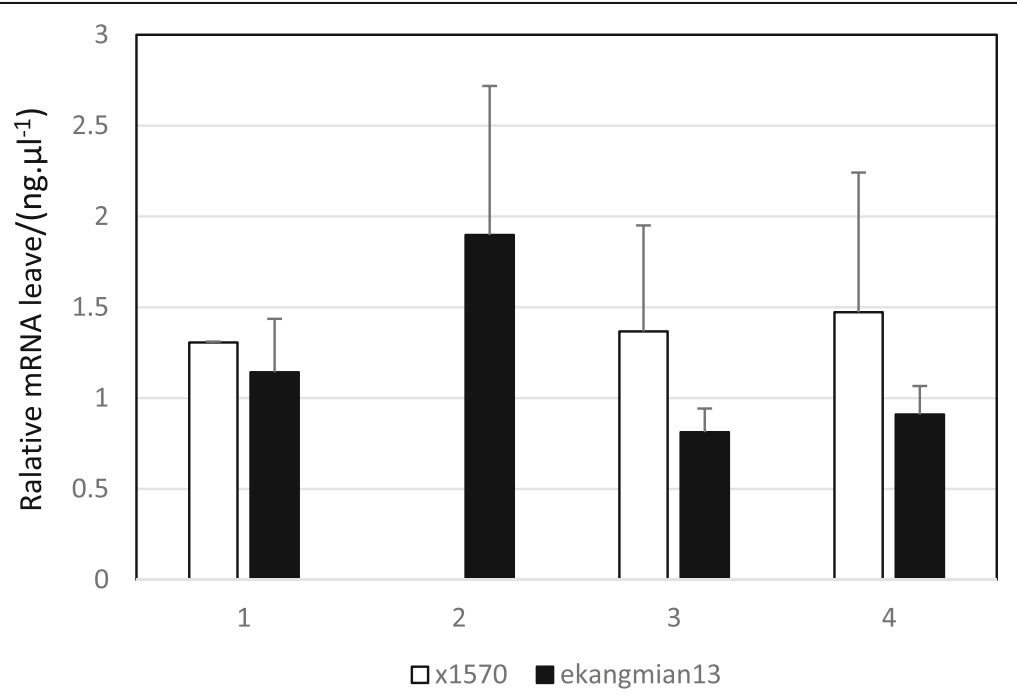

Fig. 3 1-3 represent: 1, leaves of seeding phase; 2, leaves of bud phase; 3 bud (-dp14); 4, bud (-dp9): leaves of seeding phase represents leaves from cotton plants of stage between establishment and squaring; leaves of bud phase represents leaves from squaring stage; $-d p 14$ represents buds of 14 days before flowering; - dp9 represents buds of 9 days before flowering 


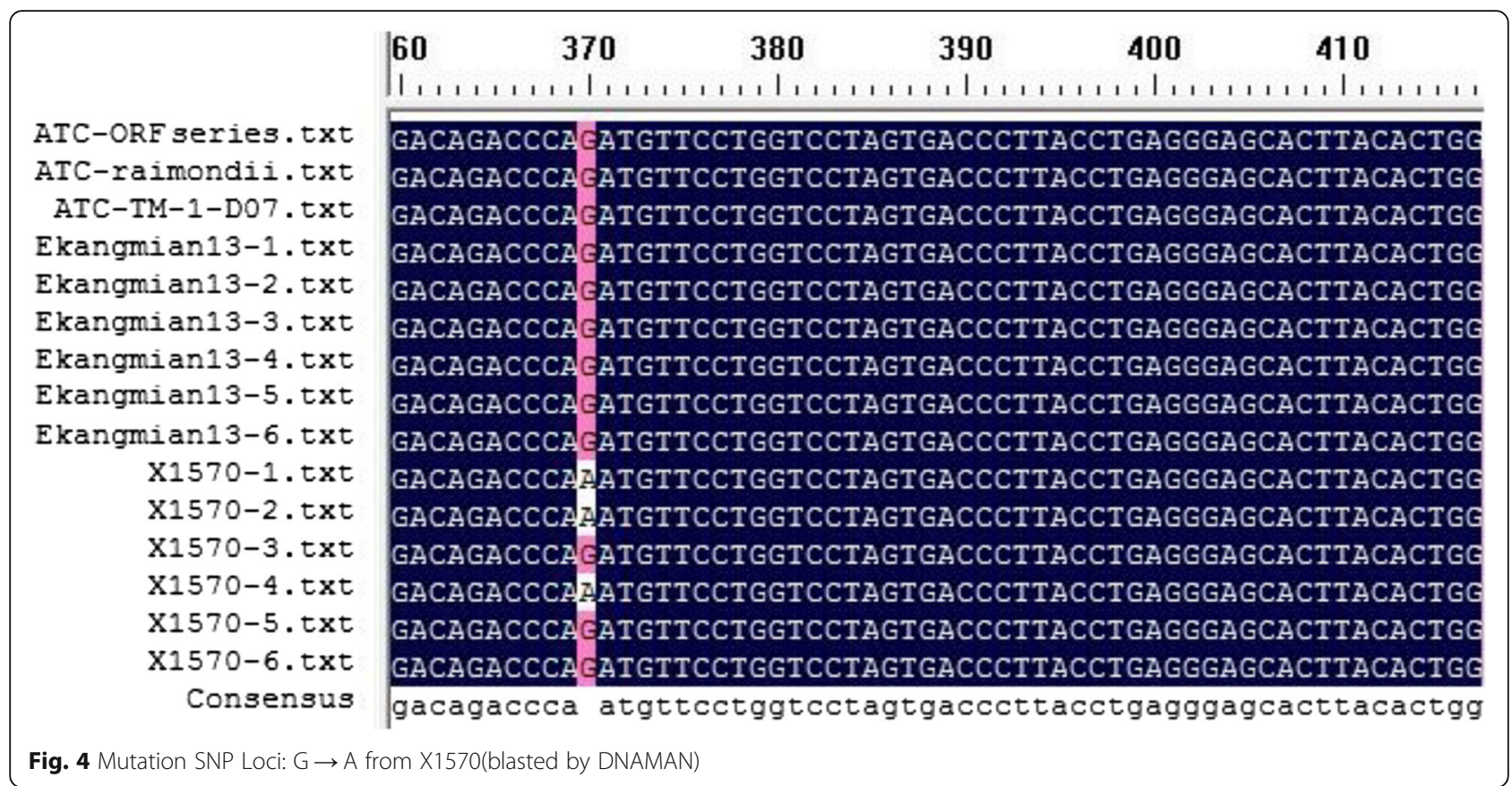

observed in the normal fruiting branch plants. Thus, it was proved that the mutation SNP_GH1570 was $100 \%$ co-segregated with short fruiting branch trait.

\section{Discussion}

The result of a chi-square test on short fruiting branch trait of $F_{2}$ populations in upland cotton indicated that the trait is a quality trait controlled by a recessive gene, the same as classical genetics and the result of Chen (Zhang et al. 2006; Hau et al. 1980; Chen et al. 2014). Because of the relatively narrow kinship and low polymorphism of $G$. hirsutum, only the SSR marker BNL3232 linked to the short fruiting branch trait was found on chromosome D07 by BSA method with SSR marker selection. There was a significant difference of the expression level of ATC gene between two cotton varieties derived from Upland cotton at the budding stage. Further sequence analysis revealed the GA mutation SNP loci of the ATC gene from X1570 was 100\% co-segregated with short fruiting branch trait by dCAPS marker technique. The SSR markers BNL3232 associated with short fruiting branch traits existed exchanging, which could not be isolated $100 \%$ totally. However, that could be achieved by using the SNP markers obtained from the trait-related genes, which was more accurate in breeding selection.

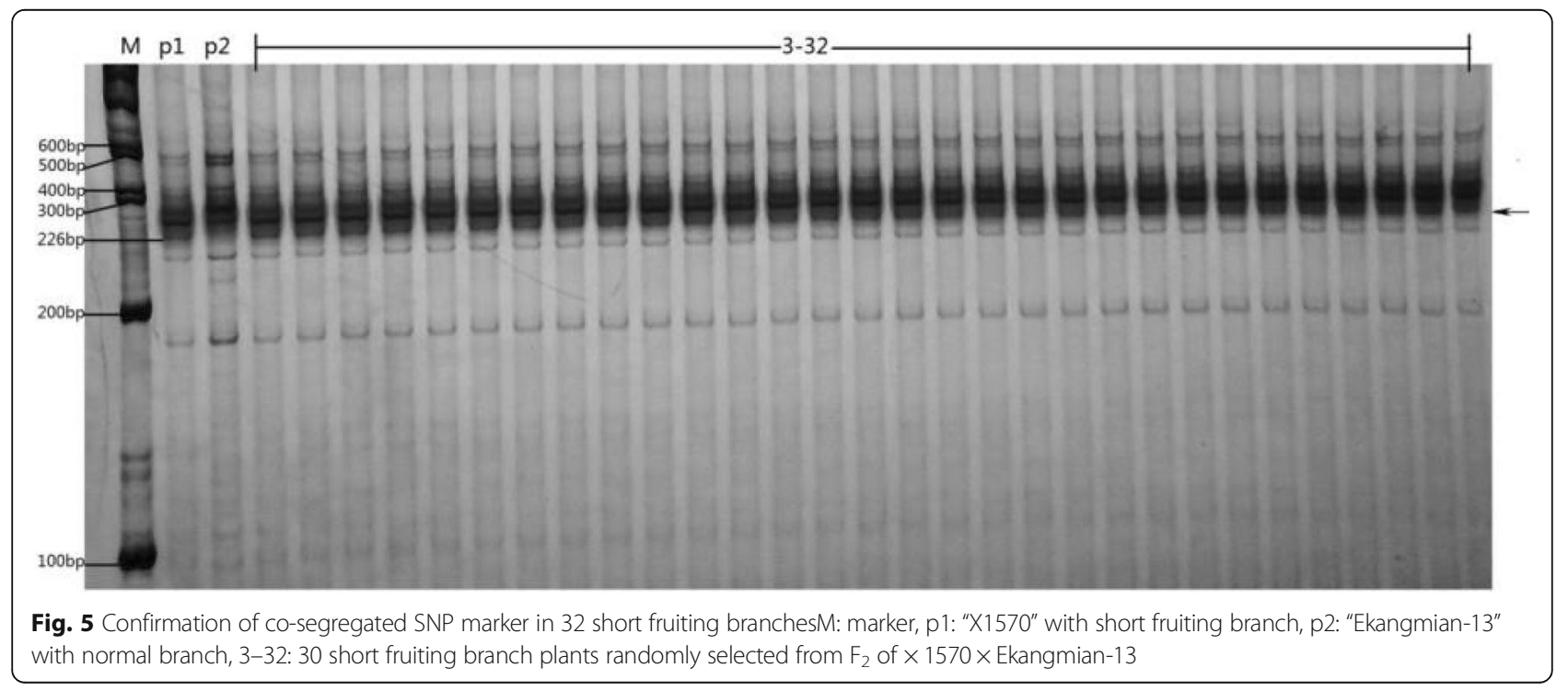


This SNP loci can be used for plant architecture selection. Because the short fruiting branch trait was controlled by a single recessive gene, the backcrossing process requires many times of selfing and identification tests to purify the short fruiting branch plants, time-consuming, costing a lot of labor and material. And the normal fruiting branch of plants are susceptible to environmental factors to be mistaken as short fruiting branches, it is difficult to distinguished from the phenotype of difference traits in the breeding process (Song et al. 2005; Dong et al. 2013; Cui 2011; Ai 2012). Therefore, the SNP_GH1570 loci was $100 \%$ co-segregated with the short fruiting branch traits, which was simple and convenient for molecular marker-assisted selection. The SNP_GH1570 loci could be identified accurately from the heterozygous plants in breeding process without interference.

The $A T C$ gene may be associated with flowering time traits. The study of Corrinne E in 2015 indicated that inhibition of $A T C$ gene expression can promote early flowering of cotton (Grover et al. 2015). In the parents or $F_{2}$ population of X1570 and Ekangmian-13, the flowering time of X1570 characterized with short fruiting branch were earlier than that of Ekangmian-13 for 8-10 days. In addition, it was reported that the ATC gene is one of the key genes controlling the flowering time, and the gene encodes the TF1 protein. The main function of this protein is to maintain the vegetative growth and the unlimited growth of the inflorescence (Fu et al. 2011). The Arabidopsis thaliana TFL1 gene inhibits forming flower primarily by inhibiting the expression of the integrating genes $L E A F Y(L F Y)$ of flowering pathway and the flower mesenchymal tissues gene AP1 and CAULIFLOWER (CAL) gene (Conti and Bradley 2007). TFL1 is another important member of TF / TFL1 gene family, which inhibits the formation of floral primordia on stem apical meristems and delays the transformation of plant from vegetative growth to reproductive growth (Hanzawa et al. 2007). Therefore, Gorai.001G121800 both controls short fruiting branch trait and flowering time. That similar phenomenon had been reported in previous research. Overexpression of PtFT gene in Prunus salicina not only resulted in early flowering, but also changed the plant architecture and increased the proliferation of nulliplex-branches (Srinivasan et al. 2012). Overexpression of AtFT gene in cotton mediated by virus could change the shape of leaves which made the palmate leaves transfer lanceolate leaves, meanwhile shorten the internodes of cotton, reduced the amount of fruit branches and axons, make the fruit more concentrated. Those changes altered plant architecture but didn't affected development of flower organ (McGarry et al. 2013).

Furthermore, it was found that the plants characterized with short fruiting branch in the $\mathrm{F}_{2}$ and $\mathrm{F}_{2: 3}$ population exhibited early flowering, had a concentrated boll opening period, and a shortened growth period. To be brief, the short fruiting branch trait was associated with early flowering and maturity traits, consistent with the characteristics of the X1570 parent line. Although those agronomic traits caused thin and weak plants at seedling stage, they didn't reduce yield, which means that the advanced maturity of short fruiting branch varieties can play an important role in the breeding of conventional and early mature varieties. Early maturity is one of the important traits for cotton cultivation following wheat or rape in a double cropping system, and fruit branch type is a determinant of plant architecture and maturity in cotton. The short fruiting branch trait improves early maturity, encourages increased planting density, and improves light energy utilization in high density cropping (Dong et al. 2011). Moreover, it is necessary to transfer the short fruiting branch trait to high-yield varieties because of its advantage, such as high planting density, without demand of pruning, suitable for picking up cotton by machine, and so on. This integration can improve the current limitations associated with plants with the short fruiting branch trait, including low lint percentage, low yield and short fiber length (Li 2012). And plants that are homozygous for the short branch trait can be identified rapidly, a benefit from these traits being controlled by a single recessive gene, which can shorten the breeding period greatly. Consequently, it is expected that appropriate varieties suitable for Yangtze River can be achieved through backcrossing the short fruiting branch mutant X1570 with high-yield, high-quality, disease-resistant materials. To achieve the purpose of simple and high-efficient planting cotton by reducing investment without reducing yield, this short fruiting branch trait mutant characterized with short growth period can be used to shorten the cotton growing season to reduce labor cost and fertilizer inputs.

\section{Conclusion}

The $F_{2}$ segregate population was constructed by using the X1570 crossed with Ekangmian-13 to analyze the short fruiting branch gene and marker-assisted selection with SNP linked to its trait. The result demonstrated that linked SSR marker BNL3232 was screened by BSA method; one SNP_GH1570 locus was found, which was totally separated from the fruiting branches trait in upland cotton. It was verified that this SNP_GH1570 was $100 \%$ co-segregated with short fruiting branch trait, which could be used for molecular assisted selection of cotton architecture in upland cotton.

\section{Acknowledgements}

The study was Sponsored by State Key Laboratory of Cotton Biology Open Fund(CB2016A07); Hubei Provincial Agricultural Science and Technology Innovation Center Support Project (2016-620-000-001-010); The National Key Technology R\&D Program (2014BAD11B0203). 


\section{Funding}

The study was Sponsored by State Key Laboratory of Cotton Biology Open Fund(CB2016A07); Hubei Provincial Agricultural Science and Technology Innovation Center Support Project (2016-620-000-001-010); The National Key Technology R\&D Program (2014BAD11B0203).

\section{Availability of data and materials}

All authors must include an "Availability of Data and Materials" section in their manuscript detailing where the data supporting their findings can be found.

\section{Authors' contributions}

Zhang YC carried out the molecular genetic studies, participated in the sequence alignment and drafted the manuscript. Feng $\mathrm{CH}$ participated in the sequence alignment. Qin HD, Bie S participated in the design of the study and performed the statistical analysis. Wang XG, Zhang JH, Xia SB conceived of the study and participated in its design and coordination and helped to draft the manuscript. All authors read and approved the final manuscript.

\section{Ethics approval and consent to participate}

Not applicable.

\section{Consent for publication}

Not applicable.

\section{Competing interests}

The authors declare that they have no competing interests.

\section{Publisher's Note}

Springer Nature remains neutral with regard to jurisdictional claims in published maps and institutional affiliations.

Received: 22 April 2018 Accepted: 28 May 2018

Published online: 30 June 2018

\section{References}

Ai N. Inheritance and QTL mapping for earliness in upland cotton. Nanjing: Nanjiang Agricultural University; 2012. p. 47-56.

Argiriou A, Michailidis G, Tsaftaris AS. Characterization and expression analysis of TERMINAL FLOWER1 homologs from cultivated alloteraploid cotton (Gossypium hirsutum) and its diploid progenitors. J Plant Physiol. 2008;165(9):1636-46.

Bednarz CW, Nichols RL. Phenological and morphological components of cotton crop maturity. Crop Sci. 2005;45(4):1497-503.

Chen W, Yao JB, Chu L, et al. Genetic mapping of the nulliplex-branch gene (gb nb1) in cotton using next-generation sequencing. Theory Application Genet. 2014. https://doi.org/10.1007/s00122-014-2425-2.

Conti L, Bradley D. Terminal flower1 is a mobile singal controlling Arabidopsis architecture. Plant Cell. 2007:19(3):767-78.

Cui QH. QTL location of earliness and fiber quality in cotton using RILs. Wuhan: Huazhong Agricultual University; 2011.

Dong N, Zhang X, Wang QL, et al. QTL mapping of prematurity and related traits in short season upland cotton. J Nucl Agric Sci. 2013;27(10):1431-40.

Dong R, Yuan HX, Gu C, et al. Cloning and primary analysis of the function of GhFTL1 gene in cotton (Gossypium hirsutum L.). Cotton Sci. 2011;23(6):515-21.

Du XM. The unification of cotton fruiting types. China Cotton. 1996;23(4):19.

Du XM, Liu GQ, Fu HQ, et al. Identification and transferring breeding of nulliplexbranch gerplasmes in upland cotton. China Cotton. 1996:23(9):7-8.

Fu JX, Wang L, Dai L. Molecular mechanism of FT/TFL1 gene family regulating the development of higher plant. Fenzi Zhiwu Yuzhong. 2011;9:1662-72.

Grover CE, Gallagher JP, Wendel JF. Candidate gene identification of flowering time genes in cotton. The Plant Genome. 2015;8(2). https://doi.org/10.3835/ plantgenome2014.12.0098.

Hanzawa Y, Money T, Bradley A. Single amino acid converts a repressor to an activator of flowering. PNAS. 2007;2(21):7748-53.

Hau B, Koto E, Schwendiman J. Examination of linkage group-III in cotton Gossypium-Hirsutum-description of a new phenotype cluster and location of genes. Cotton et Fibres Tropicales. 1980;35(4):359-67.

Hu FP, Zhou ZH. Molecuar marker and genetic mapping of five mutant genes in upland cotton. Mol Plant Breed. 2006;14(5):680-4.
Li J. Floral related genes GHSPL3 and GHLFY research in upland cotton. Shanxi, China: Northwest A\&F University; 2012

Liu F, Hu AB, Li F. Simplificatice practice and prospects of cotton production in Jianghan plain cotton region. Cotton Sci. 2013;35(6):3-7.

McGarry RC, Prewitt S, Ayre BG. Overexpression of FT in cotton affects architecture but not floral organogenesis. Plant Signal Behav. 2013;8(4):e23602.

$\mathrm{Ni} X Y$, Wang XD, Cheng $\mathrm{CH}$, et al. Constructing of DNA molecular marker linkage map and mapping of qualitative and quantitative trait in upland cotton. Cotton Sci. 2007;19(1):71-3.

Paterson AH, Brubaker $\mathrm{CL}$, Wendel JF. A rapid method for extraction of cotton (Gossypium spp.) genomic DNA suitable for RFLP or PCR analysis. Plant Mol Biol Report. 1993;11(2):122-7.

Silow RA. Evidence on chromosome homology and gene homology in the amphidiploid new world cotton. J Genet. 1946;47(2):213-21.

Song MZ, Yu SX, Fan SL, et al. Genetic analysis of main agronomic traits in short season upland cotton (G.hirsutum L.). Cotton Sci. 2005;17(2):94-8.

Song XL, Zhang TZ. Quantitative trait loci controlling plant architectural traits in cotton. Plant Sci. 2009;177(10):317-23.

Srinivasan C, Dardick C, Callahan A, et al. Plum (Prunus domestica) trees transformed with poplar FT1 result in altered architecture, dormancy requirement, and continuous flowering. PLoS One. 2012;7(7):e40715.

Thadani Kl. Inheritance of cotton character in Gossypium. Agric J India. 1923;20:37-42.

Wang ZB, Yang BX. Study on different planting density of short fruit-branch cotton. Jiangxi cotton. 2003:25(5):34-7.

Yang WY, Zhou GS, Chen Y, Chen DH. Study on the relationship between plant type and yield of high yield cotton. Jiangsu Agric Sci. 2001:2:29-30.

Yu CB, Liu SX. The breeding process and characteristics of duck-shed cotton. Agric Sci News. 1957;12:580-5.

Zhai TF. Fine Mapping of Short Fruiting Branch Gene $\mathrm{cl}$ in Cotton. Chongqing: China, Southwest University; 2015.

Zhang PT, Zhu XF, Guo WZ, et al. Inheritance and QTLs tagging for ideal plant architecture of simian three using molecular markers. Cotton Sci. 2006;18(1):13-8.

\section{Ready to submit your research? Choose BMC and benefit from:}

- fast, convenient online submission

- thorough peer review by experienced researchers in your field

- rapid publication on acceptance

- support for research data, including large and complex data types

- gold Open Access which fosters wider collaboration and increased citations

- maximum visibility for your research: over $100 \mathrm{M}$ website views per year

At BMC, research is always in progress.

Learn more biomedcentral.com/submissions 